\title{
The Differences in Influence of Approaches and Learning Styles on Learning Outcomes in the Matter Material of Class IV Students at SD IT Tadzkia, Langsa
}

\author{
Kamal Fahlevi ${ }^{1}$, KMS Amin Fauzi $^{2}$, Sumarno ${ }^{3}$ \\ ${ }^{1}$ Master Student in Univeritas Negeri Medan, Indonesia \\ ${ }^{2,3}$ Universitas Negeri Medan, Indonesia \\ kamalfahlevi2892@gmail.com
}

\begin{abstract}
In mathematics learning, the determination of the approach greatly determines student learning outcomes, because mathematics subjects are assessed for students as quite difficult subjects, this assessment appears due to the discomfort experienced by students during the learning process in class. The method used in this research is an experimental method with two-way ANOVA test analysis. This study aims to determine differences in learning outcomes through the PMR and PMR approaches based on the Math App game in terms of student learning styles. The research was conducted at SD IT Tadzkia Langsa with a total sample of 34 students. The data collection technique uses the distribution of learning style questionnaires and by conducting tests (pre-test and post-test). This study found that there were differences in learning income between PMR and PMR based on the Math App game based on a significant value of $0.045<0.05$. Then there were also differences in learning styles based on the results of the SPSS calculation with a significant value of $0.049<0.05$. Whereas in the interaction section between the learning style approach and learning style, it was found that there was an interaction between the learning style approach and the learning style with a significant value of $0.018<0.05$.
\end{abstract}

\section{Introduction}

The success and failure of students can be seen from the role of the teacher in creating a conducive learning atmosphere. Conducive learning can be realized by an effective teacher. According to Marland, teachers can be said to be effective if they have an attentive, unyielding attitude, the explanations are easy to understand and manage the class well. Meanwhile, according to Clara R Pudji Jogyanti, an effective teacher is a teacher who can improve all student abilities towards a more positive direction through teaching. (Izan, 2012: 32). So, from the two definitions above, it is understood that the role of the teacher contributes greatly to the process of learning activities. So that teachers are required to be able to understand effective learning strategies.

In this study the researcher deliberately uses a realistic mathematical approach, the researcher considers this approach to be more relevant to be implemented in learning activities, especially in mathematics learning. As said Romberg (Sriyanto, 2017: 49), "... Mathematics is more concentrated on abstract concepts". So, to understand this for 
students is very difficult if this mathematical concept is conveyed only in an expository manner. However, it takes a planning of learning activities in which each of these activities has continuous and systematic stages.

In fact, when the researcher observed the learning activities in class IV SDIT Tadzkia, it was seen that the teacher did not follow the learning activity procedures in a row which was stated in the lesson plan. Then regarding the learning approach, almost all subjects including mathematics use the scientific approach. As is well known, the scientific approach is identical to the thematic approach, in which every subject matter is combined in a theme. For high-grade mathematics such as grade 4, it is better to apply a realistic mathematics approach. This is based on several studies such as research from Susilowati (2018) in his research, namely Increasing Mathematics Learning Activities and Outcomes of Elementary School Students through Realistic Mathematic Education (RME) Models in Class IV Semester I Students at SD Negeri 4 Kradenan Kradenan District, Grobogan Regency, 2017 Academic Year / 2018. It was found that student learning outcomes in the first cycle obtained an average score of 63.81 with the incomplete category, after that it increased by 10.24 in the second cycle to 74.05 in the complete category. Then in research from Mulyati (2019) 05 with the complete category. Then in research from Mulyati (2019) 05 with complete categories. Then in research from Mulyati (2019)Based on the calculation, it is found that reject $\mathrm{HO}$ because tcount $=3.003$ is greater than $\mathrm{t}$ table $=1.67356$ at the real level $\alpha=0.05$. Thus it can be concluded that the problemsolving abilities of students on mixed arithmetic operations with RME learning are better than students who take conventional learning in grade IV SD IT Adzkia I Padang City and many other studies.

The problems in the field also show that student learning outcomes on fraction material are still low, most students have not been able to achieve minimum completeness, this is an indication that students lack mastery of fraction material. This is indicated by the low score of the students on the mean results of each indicator on the fraction material.

Table 1. Average Results on Fraction Material Indicators

\begin{tabular}{|c|l|c|}
\hline No. & \multicolumn{1}{|c|}{ Indicator } & Average Value \\
\hline 1 & Mention the elements of the fraction & 61.34 \\
\hline 2 & Shows the fractional shape of an image or concrete model & 58.42 \\
\hline 3 & Compare fractions and sort multiple fractions & 38.33 \\
\hline 4 & Describe fractions valued with concrete pictures and models & 46.52 \\
\hline
\end{tabular}

\section{Review of Literatures}

\subsection{Learning Mathematics}

Mathematics is one of the subjects taught by every school, at every level, especially in Indonesia, from elementary, junior high, high school to university. This indicates the importance of Mathematics as a subject that has been determined by the Government in the curriculum as one of the subjects in the National Examination. This indicates that Mathematics can be an accurate benchmark with a high standard error value in seeing the development and understanding of students in learning, especially in Mathematics. Talking about student development in Mathematics achievement, teachers as educators in teaching 
and educating students must understand the steps in ensuring the process of these developmental steps is going well,

In Mathematics learning, the development of each child's skills in mathematical abilities is a top priority for teachers. The recognition of numbers or numbers becomes the beginning for children in learning mathematics. Usually this basic learning has been carried out by the family or during the early childhood and kindergarten, but it cannot be denied that there are still children at the early school age who have not mastered the introduction of numbers. Usually this is based on two types of children's difficulties: 1) MD (Mathematical Difficulty), namely children who have difficulty learning mathematics, they try in any way to be able to understand these basic concepts. In general, children like this experience difficulties due to incompatibility with the learning method, or the difficulty of teachers in integrating informal knowledge that children often experience in their daily lives with formal information from schools. This is the orientation of the scope of research related to problems in the field.

\subsection{The Nature of the Realistic Mathematical Approach (PMR)}

Educational Mathematics Realistic Approach or better known as RME is a learning approach, especially in the field of mathematics, which was originally developed by Freudenthal and his colleagues at the Freundhetel institution in the Netherlands. In his view, Freudenthal said that mathematics is not a package of teaching materials that are transferred in such a way, but he considers that the learning process of mathematics is an inculcation of value through the relationship between learning and reality, and things that are often experienced by children in their daily lives.

Freundenthal also argues, the position of the teacher in a classroom serves as a guided reinvention. Where the teacher only provides a little help to students who are given the right to freely explore their ability to find mathematical concepts, formulas, and principles (Educational Development Team, 2007: 176). The development of this learning approach is based on the learning process in the context of mathematics, also known as the process of mathematization.

This process describes how the flow of the mathematics learning process should be. In this case, the mathematical process is divided into two parts: Horizontal Mathematics and Vertical Mathematics. Horizontal mathematics is the achievement in mastering mathematical concepts starting from solving problems that are relevant to everyday life. So horizontal mathematics is a process of understanding that begins with experiences often experienced by children and is associated with symbols, concepts and mathematical formulas. Meanwhile, vertical mathematics is the meaning contained in the process of horizontal mathematics.

\subsection{The Essence of PMR Game Based Math App}

Freudenthal as the main representative of the RME movement, argued that mathematics must be taught in such a way as to be useful in solving everyday life problems. He was a strong proponent of "Mathematics for All", trying to make mathematics accessible to everyone and he also advocated problem solving as a teaching method.

In the viewpoint of PMR, learners must find their starting point of learning in a rich and complex world structure, after which they must proceed with the abstract structure of the world of symbols. Other PMR researchers find it important to view concepts as problem-solving tools and discover them through their application in authentic contexts. 
By using digital technology, students can develop a deeper understanding of mathematics, because technology as a thinking tool can support students' inquiry, decision making, reflection, reasoning, and problem solving capacities. RME principles represent a context in which digital technology can provide significant assistance in teaching and learning, as digital technology itself influences the type of mathematics taught and enhances student learning. In addition, networked mobile devices contribute to mathematics education by encouraging collaboration between participants.

\subsection{The role of the Math App as a Learning Media}

Before discussing the subject of learning media, it is better if we know the meaning of media in language. The word "Media" comes from the Latin word and is the plural form of the word Medium. In terminology, the word "media" means "introduction and intermediary" (Riyana, 2012: 10). In the learning process, learning media makes it easy for teachers to convey their messages (Science) to students, so that students can properly capture the messages that the teacher has conveyed and able to do something related to the message. According to Gerlach \& Ely, media if understood in broad terms is human, material or events that build conditions, which cause students to be able to acquire knowledge, skills and attitudes (Jalinus, 2016: 2).

\subsection{The Nature of Learning Styles}

In learning activities, generally each student has different abilities in absorbing the knowledge taught. There are students who are able to understand it by writing writings written by the teacher on the board, then there are also students who like to hear an illustrated story from the teacher that illustrates an example related to the material being taught. There are even students who explore the material by practicing it directly by moving all of their limbs, this is a characteristic that becomes a measure of the extent to which students' understanding relates to the three types of learning styles in understanding Fractions material.

The characteristics of visual type children according to Howard Gardner: (DePorter and Mike Henarcki, 2005: 116)

a. Always looking, watching the lips of someone talking to him

b. Tend to use gestures when expressing something

c. Does not like speaking in front of groups, and does not like listening to other people

d. Prefers demonstrations over oral explanations

e. Usually a visual person can sit quietly in a noisy situation without being annoyed

f. Has trouble remembering verbal instructions unless written down and often asks people to help repeat them

g. Remember what is seen rather than heard

\subsection{Learning Outcomes}

Learning outcomes or achievements are the realization or expansion of a person's potential skills or capacities. Mastery of learning outcomes by a person can be seen from their behavior, both behavior in the form of mastery of knowledge, thinking skills and motor skills. Most of the activities or behavior that a person shows is the result of learning. In school the learning outcomes can be seen from the students' mastery of the subjects they take. 


\section{Research Method}

Research planned by researchers is a type of experimental research. The research will be carried out at SDIT Tadzkia Langsa. The population in this study were all students of SDIT Tadzkia Langsa for the 2020/2021 academic year consisting of parallel classes. The research sample of class IV-Abu Ubaidah bin Jarrah with a total of 24 students as the Experiment class I and Ali bin Abi Tholib with a total of 25 students as the Experiment II class. The instrument in this study was divided into 2 parts, namely giving a response questionnaire and giving a test. The questionnaire sheet contains questions related to their activities, interests and daily behavior. Each student fills in one questionnaire and each student's answer does not affect the value of his or her learning achievement. The test given in this study was in the form of choice for each question which was given a score of 0-20 and the time spent in solving it was 60 minutes. Before the test is given, the test is first tested to determine the validity and reliability of the instrument. The previously collected data should be tested using appropriate statistical tests. In this study, the statistical test used was the Two Path Anava in the form of $3 \times 2$. The test criteria, if $F>F$ table with a significant level selected from the $\mathrm{db}$ of the numerator is the appropriate $\mathrm{db}$, then $\mathrm{HO}$ is rejected. So it can be concluded that there is a difference in the average increase between the study groups tested. However, if $\mathrm{F}$ Ftable then $\mathrm{H} 0$ is accepted. Before using the Anava test, you must meet the test requirements, namely, Descriptive Statistics $\leq$

\section{Results and Discussion}

This study aims to describe student learning outcomes between student study groups using PMR and students who learn by using the application of the Mathematics-Based PMR App to find out which learning is good for current school students. The research was made based on the consideration of the current condition of some children who often spend time playing games in their daily activities. Therefore this research was conducted to see whether mathematics can be applied in student learning activities wrapped in an educational game and see the effects of their learning outcomes.

Especially in this study, learning outcomes are further reviewed through learning styles, namely kinesthetic, audio and visual. It is intended that the research results can be known more specifically to students with which learning styles have a high success rate among the three learning styles. In addition, this study also measures the interaction in the learning process related to students' initial ability factors (low, medium, high) on student learning outcomes in terms of student learning styles.

\subsection{Results}

\section{a. Student Pretest Results}

The pretest aims to determine the child's ability before carrying out learning so that the teacher can find out the extent to which students understand the fraction material to be taught, and the teacher can find out what learning designs are suitable for students to understand the material more easily. This pretest also aims to group children's abilities, namely (low, medium, high) in order to answer the formulation of problems related to interaction. To do this, the researcher distributed 20 questions in the form of choose.

Furthermore, the researcher gets a description of the students' initial abilities through standard and mean deviation. Complete data can be seen in the table below: 
Table 2. Description of Student Pretest

\begin{tabular}{|c|c|c|c|c|c|c|c|}
\hline & N & Minimum & Maximum & Sum & Mean & Std. Deviation & Variance \\
\hline PMR & 19 & 20 & 65 & 690 & 36.32 & 11,036 & 121,784 \\
PMP & 17 & 15 & 60 & 565 & 33.24 & 11,584 & 134,191 \\
Valid N & 17 & & & & & & \\
(listwise) & 17 & & & & & & \\
\hline
\end{tabular}

Each class also has a difference in the variance value and standard deviation or standard deviation. For the variance value, the PMR class has an equal value 121,784 is smaller than the student's score in the PMR Math App (PMP) class, which is 134,191 while the standard deviation value that can be ascertained also has a significant difference where the standard deviation itself is the root result of the variance, so the standard deviation value is found in the PMR class. that is, 11,036, while the class that implements learning activities using the PMR Math App (PMP) is higher than the PMR class, which is 11,548. There was a difference in the value between the mean value, the total number and the standard deviation value because the number of students in each class was different, namely the PMR class was 19 students and the PMR Math App (PMP) class had fewer students, namely 17 students. But overall in the students' initial abilities. After that, the researcher conducted a test to determine the equivalence of the students' initial ability values in the sample class using the normality test and the homogeneity test of the data.

\section{b. Student Pretest Normality Test through Learning Styles}

$T_{\text {hitung }}$ that gets is greater than. Likewise, the auditory and visual learning styles, which are found to be greater than itself, or can see through the significant level value, where each significant value is greater than 0.05 , the sample data is categorized as normal and vice versa. To test the normality of the above data due to the number of samples below 50 students, in this study the data was tested using the Shapiro Wilk normality test. So it can be concluded that the students from the two classes who were the research samples were classified as normally distributed data. $T_{\text {tabel }} T_{\text {hitung }} T_{\text {tabel }}$

\section{c. Student Pretest Normality Test on the Learning Approach}

The values in the two classes, namely the PMR class and PMR Math App (PMP), indicate that the sample data is normally distributed. Then the results of the penujina can also be seen from the significance level value. The PMR class has a significant value of $0.340>0.05$, while the PMR Math App (PMP) class has a significant value of $0.198>0.05$. This shows that if the significant value is greater than 0.05 , the data is normally distributed, so it can be concluded that the sample data in the PMR class and PMR Math App (PMP) are normally distributed. $T_{\text {hitung }}>T_{\text {tabel }}$

\section{d. Data Homogeneity Test at Student Pretest}

The value of 0.870 is greater than the value of 0.05 . So it can be concluded that students from the two classes who were the research samples were classified as homogeneous variants of data.T Sighitung

After the two prerequisite tests have been carried out, then the sample data begins to be grouped based on their mathematical abilities, namely (low, medium, and high). This grouping is based on the students' initial ability scores obtained during the pretest implementation. For students who fall into the high category, based on KAM scores. 
Meanwhile, students who belong to the moderate category get a value of <KAM. And students who belong to the low category only get KAM scores. In classes that only apply the average PMR and the standard deviation obtained is $\geq \bar{X}+S D \bar{X}-S D<\bar{X}+S D \leq \bar{X}-S D \bar{X}=36,32$ and $\mathrm{SD}=11,036$ then 47,356 and 25,284 Meanwhile, in the PMR Math App class, the average scores and standard deviation values obtained were 33.24 and $\mathrm{SD}=11.584$ then 44.824 and 21.656. So the results of the description of the categorization of the ability of PMR class students obtained 2 students classified as high, 13 students being medium and 4 students with low abilities. Meanwhile, in the PMR MathApp class 2 students were classified as high, 11 students were moderate and 4 students were classified as low. $\bar{X}+S D=\bar{X}-S D=\bar{X}=\bar{X}+S D=\bar{X}-S D=$

In this study, the samples were divided again based on their learning styles. The learning styles referred to in this study include 3 learning styles, namely: Kinesthetic, Audio and Visual. In the PMR class, there are 17 students with groupings obtained by 3 kinesthetic students, 8 audio students and 6 visual learning style students. Whereas in the PMR Math App class, students with kinesthetic learning styles consist of 4 students, 8 Audio students and 5 students with visual learning styles, the total number of students in the class is 20 students.

By knowing this learning style mapping, the researcher tries to find which learning style is suitable for the two applied learning approaches. Thus, it is hoped that learning can be created by combining student learning styles, as well as their respective abilities with the material they will learn.

\section{e. Student Mathematics Learning Posttest Data Results}

At this stage students will try to answer the questions after going through learning that takes place within a certain time and in such a setting, then students are then given a final test or what they call the Posttest and the first test results will be descriptive analysis both from the calculation of the mean, total, variance, maximum, minimum and standard deviation. The results of the analysis can be seen in the table below:

Table 3.Analys is of Posttest Results Descriptions on PMR Learning and PMR Math App (PMP)

\begin{tabular}{|l|c|c|c|c|c|c|c|}
\hline & $\mathrm{N}$ & Minimum & Maximum & Sum & Mean & Std. Deviation & Variance \\
\hline PMR & 17 & 35 & 90 & 1160 & 68.82 & 15,665 & 245,404 \\
PMP & 17 & 50 & 95 & 1295 & 76.18 & 13,408 & 179,779 \\
Valid N & 17 & & & & & & \\
(listwise) & & & & & & & \\
\hline
\end{tabular}

From the table above, it can be seen that the minimum Posttest score in the class that implements the learning process using the PMR Math App (PMP) is higher than the class taught using PMR. Likewise with the maximum score, we can see that the scores in the class that implement the PMR Math App learning are higher than the class that implements learning activities using PMR.

Then in the next data, the total value of the overall value in each class has a significant level of difference, namely in classes that apply learning using the PMR learning approach have lower overall score results compared to classes that during the study implemented learning activities with the learning approach using PMR Math App.

So, the overall mean value in the two classes can be ascertained to have different mean values. For the value in the class using the PMR learning approach has a mean value 
of 68.82. Whereas in a class that implements learning activities using the PMR Math App (PMP) learning approach has a value of 76.18 , it can be seen that the mean value in the class using the PMR Math App (PMP) is higher than the average value in the class using the PMR Learning approach.

Then the variance value, which value is used to determine the similarity of the sample or it is also called the Homogeneity test. The value obtained in a class that uses PMR Learning is lower than that in a class that implements the learning process using the PMR Math App (PMP).

Finally, for Standard Deviation or also known as standard deviation, it can be known directly through the root result of the variance value. So it can be said that the standard deviation value in the class using the PMR Learning Approach is lower than the class that applies learning activities using the PMR Math App learning approach. So that from all the values mentioned, the total number, the mean value, the maximum and minimum value, the variance and standard deviation or standard deviation in the description analysis, by considering all aspects in the description analysis it can be concluded that PMR Math (PMP) learning is better, compared to the PMR Learning Approach.

\section{f. Normality Test of Student Posttest Data through Learning Styles}

The criteria used in this test are the Shapiro Wilk test, which is classified as normally distributed if it is accepted and the data can be said to be nomally distributed, and vice versa If it is accepted and the data is not normally distributed.T Sig $>0,05 \mathrm{H}_{0} \mathrm{~T}$ Sig $\leq 0,05 \mathrm{H}_{1}$

The results of the data normality test on each learning style, namely Kinesthetic, Auditorial and Visual. For the value kinesthetic learning styleT Sig $=0.517>0.05$ then accepted, it can be said that students who tend to the kinesthetic learning style are categorized in normally distributed samples. $H_{0}$

Whereas in the Auditorial learning style, the significant level value is obtained at T Sig $=0.061>0.05$. so it is accepted, This shows that the sample data on students who tend to the Auditorial learning style are normally distributed. Finally, the sample of students who follow the Visual learning style. For the visual learning style the data normality test result value shows $0.633>0.05$ so that it is accepted, it can be concluded that the student sample data on the visual learning style are classified as normally distributed. $H_{0}$ T Sig $=H_{0}$

\section{g. Normality Test of Student Posttest Data through a Learning Approach}

Classes that use the PMR learning approach have value $T$ Sig $=0.102>0.05$ so that it is accepted, it can be said that the students in the Abu Ubadidah class who are used as research samples in classes that apply PMR in their learning activities are normally distributed. $H_{0}$

Whereas for the class that uses the PMR Math App (PMP) learning approach, it has a significance level of $0.207>0.05$ so it is accepted and rejected. So it can be said that students in Ali bin Abi Tholib's class whose learning activities use the PMR Math App are normally distributed so that both classes are eligible to meet the eligibility requirements as normal sample data.T Sig $=H_{0} H_{1}$ 


\section{h. Normality Test of Student Posttest Data at Residual Value}

The value at $\mathrm{Sig}>0.05$ is 0.076 .The basis for taking the Normality Test Decision is the guideline in the table above:

If the Sig $>0.05$, the standard residual value is normal

If the Sig $<0.05$, the standard residual value is not normal

it can be said that the residual results on the data normality test are classified as normally distributed.

\section{i. Homogeneity Test of Student Posttest Data}

The value of $\mathrm{T} \mathrm{Sig}=0.403>0.05$, this shows that the sample data used, the student posttest data is homogeneous. Then the sample data has passed the two prerequisite tests well, namely the normality test and the homogeneity test so that the sample data can be continued with data analysis

\section{j. Two Way Analysis of Variance (ANAVA Two Ways)}

In this study, a two-way analysis of variance was used to see the difference in the mean between two independent groups, each of which had different sources, namely the Abu Ubaidah class and Ali bin Abi Tholib class. Which is influenced by two factors, namely Learning Approach, namely: PMR and PMR Math App and learning styles: Kinesthetic, Audio and Visual, as well as seeing the interaction between the two factors.

Before carrying out the analysis of variance, the researcher carried out the independent $\mathrm{T}$ test to answer the first to third problem formulations related to each learning style, namely kinesthetic, theoretical and visual to both approaches, for the results of the Independent $\mathrm{T}$ test analysis can be seen in Appendix 2 while 2-way ANOVA analysis test can be seen in the table below:

Table 4. Results of the 2-line ANAVA Test Student's Posttest Data

\begin{tabular}{|l|r|r|r|r|r|}
\hline Source & Type III Sum of Squares & df & Mean Square & F & Sig. \\
\hline $\begin{array}{l}\text { Corrected } \\
\text { Model }\end{array}$ & $2927.143 \mathrm{a}$ & 5 & 585,429 & 3,781 & .010 \\
Intercept & 167282,370 & 1 & 167282,370 & 1080,397 & .000 \\
Pendektan & 711,188 & 1 & 711,188 & 4,593 & .041 \\
Style & 1041,361 & 2 & 520,681 & 3,363 & .049 \\
Approachment & 1443,991 & 2 & 721,996 & 4,663 & .018 \\
$*$ Style & 4335,357 & 28 & 154,834 & & \\
Error & 185975,000 & 34 & & & \\
Total & 7262,500 & 33 & & & \\
Corrected Total & & & & & \\
\hline
\end{tabular}

a. R Squared $=.403$ (Adjusted R Squared $=.296$ ) 


\section{k. Hypothesis Testing \\ 1. First Hypothesis}

The significance level value of 0.180 is greater than 0.05 , therefore $\mathrm{H} 0$ is accepted and $\mathrm{H} 1$ is rejected. so it can be concluded that there is no significant difference in learning outcomes for fractions seen from the PMR approach with the PMR Math App GameBased on students who have a kinesthetic learning style tendency.

\section{Second Hypothesis}

Likewise in the first hypothesis test, in this second hypothesis we are based on the Independent $\mathrm{T}$ test, obtained a significance level value of 0.644 which is greater than 0.05 , therefore $\mathrm{HO}$ is accepted and $\mathrm{H} 1$ is rejected. so it can be concluded that there is no significant difference in learning outcomes for fractions seen from the PMR approach with the PMR Math App Game based on students who have a tendency towards Auditorial learning styles.

\section{Third Hypothesis}

Furthermore, in this third hypothesis the researcher also adheres to the Independent $\mathrm{T}$ test, obtained a significance level of 0.664 greater than 0.05 , therefore $\mathrm{H} 0$ is accepted and $\mathrm{H} 1$ is rejected. So it can be concluded that there is no significant difference in learning outcomes for fractions seen from the PMR approach with the Math App-Based PMR Game for students who have a visual learning style tendency.

\section{Fourth Hypothesis}

In connection with the learning outcomes of the two learning approaches, we can see the results of the analysis of variance, from the table it can be seen that the value of the significance level is $0.041<0.05$, so it is found that $\mathrm{H} 0$ is rejected and $\mathrm{H} 1$ is accepted. So that we can conclude that there is a significant difference between the Fraction Learning Outcomes taught using the PMR approach and the Math App based PMR game.

\section{Fifth Hypothesis}

See the interactions that occur between the PMR learning approach and the PMR Math App with students' learning styles: kinesthetic, auditory and visual. Researchers draw conclusions based on the Independent $\mathrm{T}$ test, the significance level of the interaction approach and learning style is found to be 0.049 less than 0.05 , therefore $\mathrm{H} 0$ is rejected and $\mathrm{H} 1$ is accepted. so it can be concluded that there is a significant interaction between learning outcomes of fractions that are taught using the PMR approach and PMR based on the Math App game in terms of learning styles.

\subsection{Discussion}

According to Nasution (2020) to be able to teach mathematics, a teacher must be able to prepare lesson plans so mathematics lessonscan be received by students. In the era of the industrial revolution 4.0, learning emphasizes how students can understand concepts by observing real problems, process them with critical thinking, and gain experience (Tarigan, 2020). The learning process will run well if the teacher can design a great learning process, starting from planning the learning tools, learning activities in class, to evaluating them In this study also saw the interaction of learning outcomes between learning approaches and learning styles. The first interaction is between student learning outcomes with a kinesthetic learning style with students with an auditory learning style, then the interaction also occurs in student learning outcomes with kinesthetic learning 
students with visual learning style students so that it is concluded that there is an interaction between the learning approach and the learning style.

An illustration of the first interaction of the intersection that occurs between the mean value of the kinesthetic learning style, namely for the PMR value was found to be 57.5 and the PMR based on the Math App game was found to be 85 intersecting with the mean value of the auditory learning style with a PMR value of 62.5 and The PMR based on the Math App game is found to be 68. So that the point of intersection occurs at the mean point of 60.In the mean PMR value for kinesthetic and auditory learning styles, there is a difference of 5, while the mean value of PMR based on the Math App game in kinesthetic and auditory learning styles is found to be $17 .<X \leq 65$

Furthermore, for the second interaction the intersection that occurs between the mean value of the kinesthetic learning style is that the PMR value is found to be 57.5 and the PMR based on the Math App game is found to be 85 intersects with the mean value of the visual learning style with a PMR value of 79.3 and PMR. Math App based game was found to be 75.7. So that the point of intersection occurs at the mean point of 75. At the mean value of PMR for kinesthetic and visual learning styles, the difference is 21.8 , while the mean PMR value based on the Math App game in kinesthetic and auditory learning styles is found to be a difference of $9.3 .<X \leq 80$

The interaction does not occur in auditory and visual learning styles. With the mean value of the auditory learning style with a PMR value of 62.5 and the PMR based on the Math App game was found to be 68 and the mean value of the visual learning style with a PMR value of 79.3 and the PMR based on the Math App game was found to be 75.7 then it was found The difference is that the mean PMR value for kinesthetic and visual learning styles is 13.2, while the mean PMR value based on the Math App game in kinesthetic and auditory learning styles is found to be 7.7 .

\section{Conclusion}

Based on the research and discussion that researchers have done, it can be concluded that:

1) There is no significant difference in learning outcomes for fractions seen from the PMR approach with the Math App Game-Based PMR in students who have a kinesthetic learning style tendency. It is obtained a significance level value of 0.180 which is greater than 0.05 which is obtained from the results of the independent test analysis. Then in the multiple comparative test found $\mathrm{F}$ count $=10.85<\mathrm{F}$ table $=12.79$ Therefore $\mathrm{H} 0$ is accepted and $\mathrm{H} 1$ is rejected.

2) There is no significant difference in student learning outcomes seen from the realistic mathematics approach (PMR) and the PMR based on the math app game for students who have an auditory learning style tendency. This obtained a significance level value of 0.644 greater than 0.05 which was obtained from the results of the independent test analysis. Then in the multiple comparative test found $\mathrm{F}$ count $=0.532<\mathrm{F}$ table $=12.79$ so that $\mathrm{HO}$ is accepted and $\mathrm{H} 1$ is rejected.

3) There is no significant difference in student learning outcomes seen from the realistic mathematics approach (PMR) and PMR based on math app games for students who have a visual learning style tendency.This obtained a significance level of 0.664 greater than 0.05 obtained from the results of the independent test analysis. Then in the multiple comparative test found $\mathrm{F}$ count $=0.292<\mathrm{F}$ table $=12.79$ so that $\mathrm{H} 0$ is accepted and $\mathrm{H} 1$ is rejected 
4) There is a significant difference in student learning outcomes seen from the realistic mathematics approach (PMR) and the PMR based on the math app game. This obtained a significance level of 0.041 which is greater than 0.05 so that $\mathrm{H} 0$ is accepted and $\mathrm{H} 1$ is rejected

5) There is an interaction between the use of PMR and PMR based on the Math App Game on Learning Outcomes for Fractions seen from the learning style. obtained a significance level value of 0.049 greater than 0.05 so that $\mathrm{HO}$ is accepted and $\mathrm{H} 1$ is rejected.

\section{References}

Amik, F., et al. (2016). Menuju Guru dan Siswa Cerdas. Yogyakarta: Leutika Prio.

Clemant, Barody, and Sarama. (2000). Background Research on Early Mathematics. Washington DC: NGA Center Project on Early Mathematics.

DePorter, B. and Mike Henarcki. (2005). Quantum Learning. Bandung: Mizan Pustaka.

Fessakis, G. et al. (2018). The Math Trail as a Learning Activity Model for M-Learning Enhanced Realistic Mathematics Education: A Case Study in Primary Education. University of the Aegean, Rhodes, Greece, 715: 323-332

Jalinus, N. and Ambiyar. (2016). Media dan Sumber Belajar. Jakarta: Kencana.

Mulyati, A. (2019). Kemampuan Pemecahan Masalah Siswa pada Materi Operasi Hitung Campuran di Kelas IV SDIT Adzkia I Padang. Jurnal Didaktik Matematika.

Mulyono, A. (2003). Pendidikan bagi Anak berkesulitan Belajar. Jakarta: Rineka Cipta.

Nasution, Y.S., Syahputra, E., and Mulyono. (2020). The Development of Learning Instrument Using Problem Based Learning Model to Improve Critical Thinking of Junior High School Students. Budapest International Research and Critics in Linguistics and Education (BirLE) Journal Vol 3 (3): 1501-1508.

Quintero, et al. (2016). Math make Sense: A Cotructivist Approach to Teaching and Learning Mathematics. London: Imperial College Press

Riyama, C. (2012). Media Pembelajaran. Jakarta: Kementrian Agama RI.

Schunk, D.H. (2012). Learning Theories An Educational Perspective. Boston: Pearson Education Inc.

Sriyanto, H. J. (2017). Mengobarkan Api Matematika. Sukabumi: Jejak Publisher

Subini, N. (2012). Psikologi Pembelajaran. Yogyakarta. Mentari Pustaka

Sukmadinata, N.S. (2003). Landasan Psikologi Proses Pendidikan. Bandung: Remaja Rosdaka.

Susilana, R. and Cepi R. (2009). Media Pembelajaran. Bandung. Wacana Prima.

Susilowati, E. (2018). Peningkatan Aktivitas dan Hasil Belajar Matematika SD Melalui Model Realaistic Mathematic Education (RME) Pada Siswa Kelas IV Semester I di SD Negeri Kradenan Kecamatan Kradenan Kabupaten Grobogan Tahun Pelajaran 2017/2018. Jurnal PINUS, 4 (1).

Tarigan, E.E., Hasratuddin, and Fauzi, K.M.A. (2020). Development of Students Work Sheet Based on Realistic Mathematic Approach with Ethnomatematic nuanced to Improve Critical Thinking of 4th Grade Students in Primary School (SD Negeri 091358 Haranggaol, Haranggaol Horisan Sub-District). Budapest International Research and Critics in Linguistics and Education (BirLE) Journal Vol 3 (1): 133143.

Tim Pengembangan Ilmu Pendidikan. (2007). Ilmu dan Aplikasi Pendidikan. Bandung: Imperial Bhakti Utama. 